\title{
Prevalence and Determinants of Unintended Pregnancy among Women Receiving Antenatal Care Services: A Facility-Based Cross-Sectional Study in Ghana
}

\author{
Kwame Adu-Bonsaffoh ${ }^{1,2}$, Evelyn Tamma ${ }^{2}$ \& Joseph D Seffah ${ }^{1}$ \\ ${ }^{1}$ Department of Obstetrics and Gynecology, University of Ghana Medical School, Accra, Ghana \\ ${ }^{2}$ Holy Care Specialist Hospital, Accra, Ghana \\ Correspondence: Kwame Adu-Bonsaffoh, Department of Obstetrics and Gynaecology, University of Ghana \\ Medical School, Accra, Ghana. Tel: 233-206-300-480.
}

Received: May 24, 2021 Accepted: August 9, 2021 Online Published: August 23, 2021

doi:10.5539/gjhs.v13n9p100

URL: https://doi.org/10.5539/gjhs.v13n9p100

\begin{abstract}
Globally, unintended pregnancy represents an important public health challenge with significant social, economic and clinical repercussions which are worse in low-income and middle-income countries. Appropriate use of modern contraceptives averts significant proportions of unintended pregnancies and pregnancy complications. The objective of this study was to determine the prevalence and determinants of unintended pregnancy and explore modern contraceptive use among pregnant women

A cross-sectional study was conducted among pregnant women receiving antenatal care at Korle-Bu Teaching hospital in Ghana using a face-to-face structured interview. Descriptive analysis was performed and multivariable logistic regression was used to assess the determinants of unintended pregnancy.

Among the included 450 pregnant women receiving antenatal care, 155 (34.4\%) had unintended pregnancy out of which $33(21.3 \%)$ were using contraceptives prior to conception. In all, 14.2\% (64/450) were using modern contraceptives. There was a significant difference between women and their partners regarding the perception of their index pregnancy as unintended $(34.4 \%$ versus $31.6 \%$, p-value $<0.001)$. Significant determinants of unintended pregnancy include younger maternal age [aOR:5.706, 95\% CI $(1.860,19.732)]$, unmarried status [aOR:5.238, 95\%CI $(2.882,9.735)]$, previous childbirth [(aOR:2.376, 95\%CI $(1.460,4.758]$, number of pregnancies $\geq 6$ [aOR:2.640, 95\% CI $(1.210,5.854)$ ], number pregnancies $\leq 2$ [aOR:0.417, $95 \% \mathrm{CI}(0.252,0.682)$ ], previous caesarean birth [aOR:2.034, 95\%CI $(1.154,3.306)]$ and contraceptive use prior to index pregnancy [aOR:2.305 95\%CI (1.283-4.162)].

The prevalence of unintended pregnancy remains markedly high while prior contraceptive use was relatively low among women receiving antenatal care. Evidence-based interventions including specialized client education are vital in improving optimal use of contraceptive services. We recommend further research including community-based qualitative studies to better understand the factors associated with contraceptive uptake and outcomes of unintended pregnancy.
\end{abstract}

Keywords: unintended pregnancy, modern contraceptives, determinants, prevalence, Ghana

\section{Introduction}

Pregnancy that occurs sooner than expected (mistimed) and or when the woman has no desire to have more children at the time of conception (unwanted) are collectively referred to as unintended pregnancy (Santelli et al., 2003). Varying across countries, unintended pregnancy remains a subject of global concern because it is a major public health challenge with significant social, economic and clinical consequences. Global data analysis between 2010 and 2014 shows that $44 \%$ of pregnancies were unintended worldwide with greater proportion resulting in abortion (Bearak, Popinchalk, Alkema, \& Sedgh, 2018). The magnitude of unintended pregnancy burden in low and middle-income countries (LMICs) is comparatively far higher compared to the high-income countries (Sedgh et al., 2014). In Ghana, the proportion of unintended birth declined marginally from $42 \%$ to $31 \%$ between the period of 1993 to 2014 (GHS and Ghana Statistical Service (GSS), 2015). The burden of unintended pregnancy remains unacceptably high considering the potential adverse effects and the associated economic ramifications 
(Ghana Statistical Service (GSS), 2012).

Women with unintended pregnancies are more likely to delay or receive inadequate prenatal care with increased potential of health problems for the mother and unborn baby. Previous studies have shown that unintended pregnancies especially unwanted pregnancies are related to preterm delivery (Mohllajee et al., 2007; Orr et al., 2008) and premature rupture of membranes (Orr et al., 2008). Also, unintended pregnancy constitutes a specific risk factor for maternal mortality with far higher detriments in LMICs. Campbell and Graham demonstrated that about $25-40 \%$ of maternal deaths could be avoided if unwanted and unplanned pregnancies were prevented (Campbell \& Graham, 2006). Unfortunately, there is a wide inequality in maternal mortality risk with apparent worse skewness to LMICs. Recent data from World health organization (WHO) indicates global lifetime risk of maternal death of 1 in 190 women with 1 in 5400 and 1 in 38 in the high-income regions and Sub-Saharan Africa respectively (WHO, 2019).

Globally, unintended pregnancies generally result in unplanned births or abortions. Recent global report indicates the about $59 \%$ and $55 \%$ of unintended pregnancies result in abortion in high and low income countries respectively (Bearak et al., 2018). Between 2010 and 2014, over 25 million unsafe abortions occurred annually with approximately $97 \%$ of these reported in the developing countries (Ganatra et al., 2017). Potentially, unsafe abortions are associated with multiple complications such as septic shock, post-abortal pelvic inflammatory disease and severe maternal morbidity and mortality (Melese et al., 2017). A related study in Ghana reported a 32.6\% prevalence of unintended pregnancy occurred among women with pre-eclampsia, a leading cause of maternal death in most tertiary hospitals in the country, and about $57 \%$ were not on any modern contraceptives (Adu-Bonsaffoh \& Seffah, 2015). Complications of induced abortions still accounts for significant proportion of maternal deaths in the country although there has been a significant reduction over the past decade (GHS and Ghana Statistical Service (GSS), 2018). Other untoward accompaniments of unintended pregnancies include considerable increase in economic constraints and stress on families and the society (Engstrand \& Kallner, 2018; Sapkota et al., 2015).

Relatedly, 26\% of women between the ages of 15-49 have unmet need for contraception in Ghana of which unmet need for limiting and spacing accounts for $10 \%$ and $16 \%$ respectively. On the other hand, national contraceptive prevalence rate is estimated as $34.7 \%$ which indicates more room for improvement in access to contraception (Ghana Statistical Service (GSS), 2012). Also, maternal mortality ratio (MMR) remains relatively high (308 per 100,000 live births) despite implementation of several national interventional programs to improve maternal health in the country (WHO, 2019). In Korle-Bu Teaching Hospital, the current study site, the MMR has not improved appreciably over the past decade with a recently reported figure of 915 per 100,000 livebirths (Adu-Bonsaffoh et al., 2013).

As part of the institutional effort to improve maternal health and reduce maternal morbidity and mortality in the tertiary facility and the country as whole, there is a need to explore the burden of unintended pregnancy in the hospital to provide evidence for improving the quality of reproductive health care. Although several institutional policies have been implemented to reduce pregnancy complications and maternal deaths the burden of unintended pregnancy has not been adequately explored. The objective of this study was to determine the prevalence and determinants of unintended pregnancy and explore modern contraceptive use among women attending antenatal clinic at a tertiary hospital in Ghana.

\section{Materials and Methods}

\subsection{Study Design and Site}

This was a cross sectional study conducted at the Korle Bu Teaching Hospital (KBTH) between $1^{\text {st }}$ June and $31^{\text {st }}$ July 2013. Korle Bu Teaching Hospital is the largest tertiary hospital in Ghana located in the capital, Accra. Serving a population of over three million people, this tertiary referral hospital supervises approximately 10,000 deliveries annually. The National health insurance free delivery scheme covers all deliveries at the hospital. The hospital serves about 120 pregnant women daily at the antenatal clinic.

\subsection{Study Population and Sample size Calculation}

Inclusion criteria consisted of pregnant women attending antenatal clinic and who provided informed consent to be included in the study. We excluded women in labor, those who presented with emergency conditions or complications and those who declined to be included in the study.

The sample size for this study was calculated based on the primary objective of determining the prevalence of unintended pregnancy among the pregnant women receiving antenatal care. In the calculation, the estimated proportion or prevalence of unintended pregnancies in Ghana of 40\% (GHS and Ghana Statistical Service (GSS), 
2009) was used with the coefficient of significance (1.96) for significance level $(\alpha)$ of $5 \%$ and the allowable error margin fixed at $5 \%$. The minimum sample size required was 424 after $15 \%$ adjustment to cater for inconsistencies and incompleteness.

\subsection{Ethics Approval and Consent to Participate}

The study protocol was approved by the Ethical and Protocol Review Committee of the University of Ghana Medical School (Protocol ID Number: MS-Et/M.7-P4.7/2012-13). Written informed consent was granted by all the participants prior to collection of data.

\subsection{Sampling Procedure and Recruitment}

The study involved a face-to-face interview of women attending antenatal clinics based on a structured questionnaire. The study participants were recruited using convenient sampling. The study participants were interviewed after they had received antenatal care services and provided informed consent. This exit interview conducted after receiving antenatal care was to encourage the study participants to provide clearly objective responses to the questionnaire without fear of retribution. The interview usually took at most 30 minutes and all the study participants provided written informed consent prior to the data collection. The study participants were informed that participation in the study was purely voluntary and that failure to participate or discontinuation would not have any adverse effect on the quality of their medical care. In order to get the participants to respond to the sensitive questions and also for them to feel very comfortable, well trained female data collectors were used. The pregnancy intention was coded as intended or unintended. If the respondent was looking forward to the pregnancy or wanted it at the time of conception then it was considered intended. On the other hand, if the respondent, at the time of conception, would have wanted the pregnancy later on or did not want it at all, then it was considered unintended (Santelli et al., 2003).

\subsection{Dependent and Independent Variables}

The main primary outcome (dependent) variable was the prevalence of unintended pregnancy among pregnant women obtaining antenatal care services. Unintended pregnancy was defined as gestation occurring sooner than expected (mistimed) and or when the woman has no desire for more children at the time of conception (unwanted) (Santelli et al., 2003).

The independent variables in this study include socio-demographic characteristics such as maternal age, marital status (married/co-habitation, single) educational status and residence (urban, urban slums/rural). The obstetric independent variables were parity (previous births), gravidity (number of pregnancies), previous cesarean section and contraceptive use prior to index pregnancy.

\subsection{Data Analysis}

The data were entered into Microsoft Excel spread sheet and analyzed using SPSS version 22 and R (version 3.6.3). The outcome (dependent) variable was pregnancy intention which is dichotomous and coded as intended and unintended. Initial descriptive analyses were performed, and the results were presented in percentages. The effects of the various factors on the dependent variable were first determined using the bivariate logistic regression which involved fitting the dependent variable as a function of the individual independent variables. The multivariate logistic regression was then fitted to determine the significant determinants of unintended pregnancy. There was a significant interaction between parity and gravidity groups and the two variables were not included in the same logistic regression model. A significant result was considered at a $\mathrm{p}$ value of less than 0.05 . 


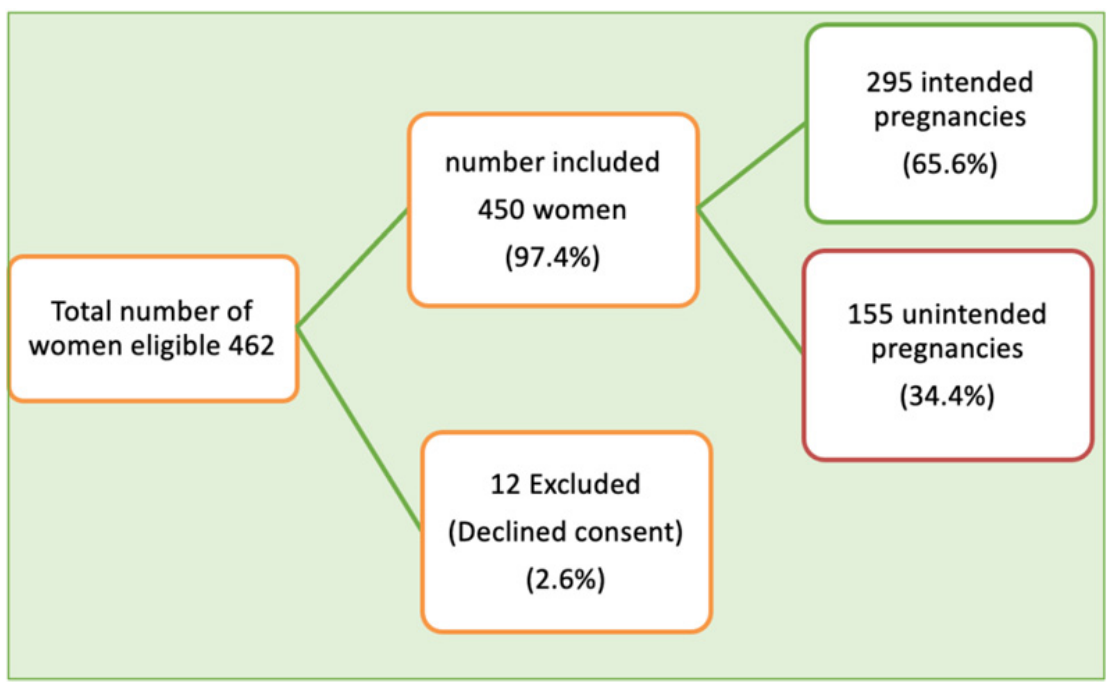

Figure 1. Flow chart showing recruitment of women with intended and unintended pregnancies

\section{Results}

In this study, 462 women were approached for inclusion out of which 450 consented and were included with 12 declining to take part in the study (Figure 1).

\subsection{Background Characteristics}

Table 1 shows the characteristics of women with intended and unintended pregnancies. Among the 450 antenatal clients included in the study, 335 (74.4\%) were between the ages of 20-34 with the mean maternal age of $30.6 \pm$ 5.2 years. More than half of the respondents [282 (62.7\%)] lived in the urban area. Also, $28.7 \%$ and $16.4 \%$ have had tertiary level and primary or no education respectively. Majority of the women $(84.2 \%)$ were married or cohabitating. Among the study participants, $30 \%$ were nulliparous with $70 \%$ having a history of one or more childbirths (Table 1). Women of gravidity $1-2$ and 6 or more represented $47.1 \%$ and $8 \%$ respectively with 78 $(17.3 \%)$ having a history of previous induced termination of pregnancy. Also, 25.6\% (115/450) of respondents had a history of previous cesarean. Majority of the participants (71.4\%) had pregnancy interval of at least two years whereas $28.6 \%$ had pregnancy interval of less than two years.

Table 1. Characteristics of women with intended and unintended pregnancies

\begin{tabular}{|c|c|c|c|c|}
\hline Variable & $\begin{array}{l}\text { Total }(\mathrm{N}=450) \\
\text { n (\%) }\end{array}$ & $\begin{array}{l}\text { Intended Pregnancy } \\
\text { n }(\%)\end{array}$ & $\begin{array}{l}\text { Unintended pregnancy } \\
\text { n (\%) }\end{array}$ & $\rho$ value \\
\hline Maternal Age & & & & 0.026 \\
\hline$<20$ & $11(2.4)$ & $3(27.3)$ & $8(72.7)$ & \\
\hline $20-34$ & $335(74.4)$ & $223(66.6)$ & $112(33.4)$ & \\
\hline$\geq 35$ & $104(23.1)$ & $69(66.3)$ & $35(33.7)$ & \\
\hline Marital status & & & & 0.000 \\
\hline Married/cohabitation & $379(84.2)$ & $269(71.0)$ & $110(29.0)$ & \\
\hline Single & $71(15.8)$ & $26(36.6)$ & $45(63.4)$ & \\
\hline Education & & & & 0.027 \\
\hline Primary/None & $74(16.4)$ & $43(58.1)$ & 31(41.9) & \\
\hline Junior high school (JHS) & $126(28.0)$ & $74(58.7)$ & $52(41.3)$ & \\
\hline Senior high school (SHS) & $121(26.9)$ & $82(67.8)$ & $39(32.2)$ & \\
\hline Tertiary & $129(28.7)$ & $96(74.4)$ & $33(25.6)$ & \\
\hline
\end{tabular}




\begin{tabular}{|c|c|c|c|c|}
\hline Gravidity group & & & & 0.000 \\
\hline $1-2$ & $212(47.1)$ & $157(74.1)$ & $55(25.9)$ & \\
\hline $3-5$ & $202(44.9)$ & $122(60.4)$ & $80(39.6)$ & \\
\hline$\geq 6$ & $36(8.0)$ & $16(44.4)$ & $20(55.6)$ & \\
\hline Parity group & & & & 0.002 \\
\hline Nulliparous & $135(30.0)$ & $103(76.3)$ & $32(23.7)$ & \\
\hline Previous birth ( $\geq 1$ parity) & $315(70.0)$ & $192(61.0)$ & $123(39.0)$ & \\
\hline Prior contraceptive use & & & & 0.003 \\
\hline Yes & $64(14.2)$ & $31(48.4)$ & $33(51.6)$ & \\
\hline No & $386(85.8)$ & $264(68.4)$ & $122(31.6)$ & \\
\hline Previous cesarean & & & & 0.043 \\
\hline Yes & $115(25.6)$ & $66(57.4)$ & 49 (42.6) & \\
\hline No & $335(74.4)$ & $227(68.4)$ & $106(31.6)$ & \\
\hline Pregnancy interval $^{\mathrm{m}}$ & & & & 0.912 \\
\hline$<24$ months & $97(28.6)$ & $60(61.9)$ & $37(38.1)$ & \\
\hline$\geq 24$ months & 242 (71.4) & $153(63.2)$ & $89(36.8)$ & \\
\hline
\end{tabular}

$\mathrm{m}_{=}=$missing values (not applicable to 111 participants).

\subsection{Unintended Pregnancy and Contraceptive Use among Respondents}

Unintended pregnancy was experienced by $34.4 \%$ out of 450 respondents with highest proportions recorded among women younger than 20 years $(72.7 \%)$, women of gravidity of 6 and more $(55.6 \%)$, those with parity $1-2$ $(65.3 \%)$ and JHS level of education $(41.3 \%)$ as shown in Table 1. Similarly, high proportions of unintended pregnancy were reported by respondents living in the urban slums (38.7\%), single women (63.4\%), women with a history of previous cesarean sections (41.4\%) and those with pregnancy intervals less than 24 months (37.5\%). There was also higher frequency of unintended pregnancies among women who were using contraceptives before their index pregnancies compared to those who were not (51.6\%) versus (31.6\%). From the opinions of the male partners of respondents, $31.6 \%(n=142)$ out of 449 described the index pregnancies as unintended. There was a significant difference between women and their male partners regarding the perception of pregnancy as unintended at the time of conception ( $34.4 \%$ versus $31.6 \%$, p-value $<0.001$ )

Regarding contraception, 438 (97.3\%) had heard about modern contraceptive and 110 (24.4\%) had ever used contraceptives. Sixty-four (14.2\%) women were using contraception prior to their index pregnancies out of which $33(51.6 \%)$ reported unintended pregnancy. The use contraceptives before the index pregnancy was most prevalent among women aged 20-34 (22.3\%), those with tertiary level of education (27.3\%) and women of gravidity 6 or more $(25.0 \%)$. Similarly, the frequencies of modern contraceptive use prior to index pregnancies were higher among single women $(22.2 \%)$, those with no history of previous cesarean $(25.2 \%)$ and those with pregnancy interval of less than 24 months (21.6\%). Among the 64 women who used contraceptives before their current pregnancies, the pills were the most commonly used $38(59.4 \%)$ followed by the injectables $16(25.0 \%)$, implants $5(7.8 \%)$, intrauterine device $3(4.7 \%)$ and others $2(3.1 \%)$. Among the women who experienced unintended pregnancy whilst using contraceptives, $20(60.1 \%), 8(24.2 \%)$ and $3(9.1 \%)$ were using pills, injectables and implants respectively. There was no contraceptive failure among the respondents who used intrauterine device.

Table 2 shows the characteristics of women who experienced unintended pregnancy and had a prior modern contraceptive use. None of the independent variables showed statistically significant association with the use of contraceptive before index pregnancy. 
Table 2. Characteristics of women with unintended pregnancy and modern contraceptive use

\begin{tabular}{|c|c|c|c|c|}
\hline \multirow{2}{*}{ Variable } & \multicolumn{4}{|c|}{ Modern contraceptive use prior to index pregnancy } \\
\hline & No of UP (155) & No $[\mathbf{n}(\%)]$ & Yes $[\mathbf{n}(\%)]$ & $\rho$ value \\
\hline Maternal age (years) & & & & 1.00 \\
\hline$<20$ & $8(5.2)$ & $7(87.5)$ & $1(12.5)$ & \\
\hline $20-34$ & $112(72.3)$ & $87(77.7)$ & $25(22.3)$ & \\
\hline$\geq 35$ & $35(22.6)$ & $28(80.0)$ & $7(20.0)$ & \\
\hline Marital status & & & & 0.856 \\
\hline Married/cohabitation & $110(71.0)$ & $87(79.1)$ & $23(20.9)$ & \\
\hline Single & $45(29.0)$ & $35(77.8)$ & $10(22.2)$ & \\
\hline Education & & & & 0.150 \\
\hline Primary/None & $31(20.0)$ & $29(93.5)$ & $2(6.5)$ & \\
\hline Junior high school & $52(33.5)$ & $40(76.9)$ & $12(23.1)$ & \\
\hline Senior high school & $39(25.2)$ & $29(74.4)$ & $10(25.6)$ & \\
\hline Tertiary & $33(21.3)$ & $24(72.7)$ & $9(27.3)$ & \\
\hline Gravidity group & & & & 0.535 \\
\hline $1-2$ & $55(35.5)$ & $46(83.6)$ & $9(16.4)$ & \\
\hline $3-5$ & $80(51.6)$ & $61(76.2)$ & $19(23.8)$ & \\
\hline$\geq 6$ & $20(12.9)$ & $15(75.0)$ & $5(25.0)$ & \\
\hline Parity groups & & & & 0.458 \\
\hline Nulliparous & $32(20.7)$ & $24(75.0)$ & $8(25.0)$ & \\
\hline Previous birth ( $\geq 1$ parity) & $123(79.3)$ & $98(79.7)$ & $25(20.3)$ & \\
\hline Previous cesarean & & & & 0.073 \\
\hline No & $107(69.0)$ & $80(74.8)$ & $27(25.2)$ & \\
\hline Yes & $48(31.0)$ & $42(87.5)$ & $6(12.5)$ & \\
\hline Pregnancy interval $^{\mathrm{m}}$ & & & & 0.860 \\
\hline$<24$ & $37(29.4)$ & $29(78.4)$ & $8(21.6)$ & \\
\hline$\geq 24$ & $89(70.6)$ & $71(79.8)$ & $18(20.2)$ & \\
\hline
\end{tabular}

$\mathrm{m}_{=}=$missing values (not applicable to 29 participants).

\subsection{Determinants of Unintended Pregnancy}

The results of the bivariate analysis in Table 3 shows that maternal age, gravidity, parity (previous childbirth), marital status, education status and contraceptive use before index pregnancy were significantly associated with unintended pregnancy. The multivariate logistic regression showed that younger maternal age, unmarried status, previous childbirth, number of pregnancies $\geq 6$, previous caesarean birth and contraceptive use prior to index pregnancy were significant factors influencing unintended pregnancy in this study. Previous number of pregnancies $\leq 2$ was associated with reduced risk of unintended pregnancy. 
Table 3. Bivariate and multivariate logistic regression of unintended pregnancy and determinant variables

\begin{tabular}{|c|c|c|c|c|c|c|}
\hline Variable & OR & $95 \% \mathrm{CI}$ & $\rho$ value & $\mathrm{aOR}^{\mathrm{a}}$ & $95 \% \mathrm{CI}$ & $\rho$ value \\
\hline \multicolumn{7}{|l|}{ Maternal age (years) } \\
\hline$<20$ & 4.018 & $1.392,13.164$ & 0.013 & 5.706 & $1.860,19.732$ & 0.003 \\
\hline $20-34$ & Ref & & & Ref & & \\
\hline$\geq 35$ & 1.019 & $0.634,1.619$ & 0.937 & 0.656 & $0.378,1.116$ & 0.126 \\
\hline \multicolumn{7}{|l|}{ Marital status } \\
\hline Married/cohabitating & Ref & & & Ref & & \\
\hline Single & 4.233 & $2.506,7.281$ & 0.000 & 5.238 & $2.882,9.735$ & 0.000 \\
\hline \multicolumn{7}{|l|}{ Education } \\
\hline Primary/None & Ref & & & Ref & & \\
\hline Junior high school & 0.975 & $0.545,1.751$ & 0.931 & 0.947 & $0.496,1.814$ & 0.868 \\
\hline Senior high school & 0.660 & $0.362,1.202$ & 0.173 & 0.697 & $0.360,1.350$ & 0.283 \\
\hline Tertiary & 0.477 & $0.259,0.875$ & 0.017 & 0.786 & $0.388,1.595$ & 0.503 \\
\hline \multicolumn{7}{|l|}{ Gravidity group } \\
\hline $1-2$ & 0.534 & $0.351,0.867$ & 0.003 & 0.417 & $0.252,0.682$ & 0.001 \\
\hline $3-5$ & Ref & & & Ref & & \\
\hline$\geq 6$ & 1.906 & $0.905,3.945$ & 0.077 & 2.640 & $1.210,5.854$ & 0.015 \\
\hline \multicolumn{7}{|l|}{ Parity group ${ }^{b}$} \\
\hline Nulliparous & Ref & & & Ref & & \\
\hline Previous birth ( $\geq 1$ parity) & 2.062 & $1.318,3.292$ & 0.002 & 2.376 & $1.460,4.758$ & 0.002 \\
\hline \multicolumn{7}{|l|}{ Previous cesarean } \\
\hline No & Ref & & & Ref & & \\
\hline Yes & 1.604 & $1.035,2.477$ & 0.034 & 2.034 & $1.154,3.306$ & 0.004 \\
\hline \multicolumn{7}{|l|}{ Prior contraceptive use } \\
\hline No & Ref & & & Ref & & \\
\hline Yes & 2.304 & $1.348,3.947$ & 0.002 & 2.305 & $1.283,4.162$ & 0.005 \\
\hline
\end{tabular}

adjusted for adjusted for all the variables in the table except parity group; ${ }^{b}$ adjusted for all variables except gravidity group.

\section{Discussion}

In this study, the prevalence of unintended pregnancy determined among pregnant women receiving antenatal care was $34.4 \%$. Contraceptive prevalence rate among women with unintended pregnancy was $21.3 \%$ and about $50 \%$ reported unintended pregnancy. There was a significant difference between women's and their male partners' perspectives regarding pregnancy intention (intended or unintended) at the time of conception. The main determinants associated with unintended pregnancies were younger maternal age, unmarried status, previous childbirth (parity) and number of pregnancies (gravidity), previous caesarean birth, and contraceptive usage prior to index pregnancy.

The prevalence of unintended pregnancy determined in this study is consistent with $33 \%$ reported for the African continent (Sedgh et al., 2014) but moderately lower than the prevalence $40 \%$ and $43.8 \%$ reported by Nyarko in Ghana (Nyarko, 2019) and Lawani et al in Nigeria (Lawani et al., 2018) respectively. The wide variations in the prevalence of unintended pregnancy determined in our study and the national figure reported by Nyarko relates to the different contexts of the two studies with the latter being a secondary analysis of countrywide national survey. In the tertiary centre, more complicated cases are referred for specialist care and it is likely that some of these clients may have received some form of fertility treatment accounting for the lower prevalence of unintended pregnancy. 
Determinants of unintended pregnancy determined in our study were varied including younger maternal age (less than 20 years) compared to women between 20 and 34 years of age. The finding of significant association between younger maternal age and unintended pregnancy is consistent with other local and international studies from Kenya, Pakistan, Brazil, Papua New Guinea, Tanzania, Canada and Ghana (De Coelho et al., 2012; Exavery et al., 2014; Ghana Statistical Service (GSS), 2012; Habib et al., 2017; Oulman et al., 2015; Sanga et al., 2014), with contemporary adolescents becoming sexually active earlier than in the past (Maja, 2007). Adolescent relationships are likely to be short-lived and unstable. Moreover, couples in unstable relationships are less likely to plan sexual intimacy or childbirth (Loewenstein \& Furstenberg, 1991). In Ghana, women less than 20 years are more likely to be in the senior high school or learning various vocations and pregnancies occurring at such times are most likely described as unexpected or mistimed (Ameyaw, 2018).

In this study, previous childbirth ( $\geq 1$ parity) and high number of pregnancies $(\geq 6)$ were found to be significantly associated with increased occurrence of unintended pregnancy whilst women with lower number of pregnancies $(\leq 2)$ had a lower risk. Similarly, previous caesarean birth which is related to multiparity was found to be associated with increased frequency of unintended pregnancy. Women with previous births were at higher risks of experiencing unintended pregnancies compared to nulliparous women and this finding is comparable to other studies (Eliason et al., 2014; Fite, Mohammedamin, \& Abebe, 2018; Habib et al., 2017; Johnson \& Madise, 2011; Mohammed et al., 2016). This finding of significant association between previous birth and unintended pregnancy is partly because multiparous women might have attained the optimum family sizes required with minimal expectation of future childbearing. Also. The preference for a particular gender by a couple, for instance, a male child, might result in multiple childbirths than originally intended (Eliason et al., 2014). Also, there is a cultural belief among some tribes in Ghana which demands that another child must be born after the birth of twins, to ensure the optimal survival of twins or triplets. Hence, regardless of the number of children a couple already has, they are tempted to have another child after twin births and this indigenous culture partly increases the prevalence of unintended births. Similarly, women who have two or more children already are compelled in their new marriages to have at least a child to appease their in-laws or husbands and to secure their new marriages. This belief partly explains the significant difference in the prevalence of unintended pregnancy from the perspectives of women and their partners.

In our study, unmarried status was also significantly associated with occurrence of unintended pregnancy, consistent with other studies conducted in Ghana, Kenya, Ethiopia, Tanzania and other parts of the world (Agbeno et al., 2018; Eliason et al., 2014; Exavery et al., 2014; Fite et al., 2018; Haffejee et al., 2018; Johnson \& Madise, 2011; Mohammed et al., 2016; Sanga et al., 2014). Most of the time, married or cohabitating women are in more stable relationships and so they are more likely to plan sexual intimacy. Divorced and single women are more likely to have coital activities for pleasure and not for procreation (Mohammed et al., 2016). Single women in some communities in Ghana do not feel comfortable going for contraceptives because they are afraid of being judged or labeled promiscuous. Therefore, any unplanned and unprotected sexual activities might result in unplanned pregnancy.

Intriguingly, women who reported contraceptive use before their index pregnancies were twice more likely to experience unintended pregnancy compared to those who were not using any contraceptives. Generally, non-use of contraceptives is associated with higher odds of experiencing unintended pregnancies (Habib et al., 2017; Sanga et al., 2014). In this study, the high frequency of unintended pregnancy in association with contraceptives use prior to their current pregnancies might partly be explained by contraceptive failure or inappropriate use of the contraceptives. Bradley et al reported contraceptive failure rates of $13.2 \%, 5.2 \%, 11.2 \%$ and $20.8 \%$ for Kenya, Malawi, Tanzania and Zimbabwe respectively (Bradley et al., 2011). However, our finding is consistent with the study by Polis et al (Polis et al., 2016) who reported wide variations in contraceptive failure rate in 43 countries. In their review, contraceptive failure was generally higher in younger women but older women in West Africa experienced higher failure rates for implants, pills and condoms. Globally, contraceptive failure is an important determinant for unintended pregnancy and this comprises both method-related and user-related failures (Polis et al., 2016).

In this study, $21.3 \%$ of the women with unintended pregnancy used contraceptives before their current pregnancies whilst $78.7 \%$ were not using any form of contraceptives. The low prevalence of contraceptive use may be due several factors including lack of sexually activity until pregnancy was desired, newly married couple who desire pregnancy and fear of side effects. In Ghana, the current contraceptive prevalence rate has been reported as $25 \%$ (GHS and Ghana Statistical Service, 2018) which is lower than 28.5\% estimated for the African continent and far lower than the global figure of $57.4 \%$ (WHO, 2018). Appropriate goal-oriented education programs on contraceptives should have a more effective approach to adequately address specific needs of different phenotypes 
of women who are at a greater risk of unintended pregnancy. A very friendly and warm approach in dealing with women of different socio-economic backgrounds are very influential in the choices of contraceptives, confidence of clients and use of contraceptives (Maja, 2007).

The strength of this study relates to its cross-sectional nature with an exit data collection component that encouraged the respondents to express their views without retribution or fear of not receiving the appropriate clinical care. The limitations of the study include the non-inclusion of the qualitative component which would have further explored the relativity of unintended pregnancy to contraceptive use and failure. Another limitation is related to the self-report approach in the data collection and possibility of recall bias. Also, the reasons for contraceptive failure including the challenges associated with typical use were not explored to provide further insight into to the high prevalence unintended pregnancy among women who used contraceptives prior to their index pregnancies, and this is considered a limitation of the study.

\section{Conclusion}

There is high prevalence of unintended pregnancy but relatively low prior contraceptive use among pregnant women receiving antenatal care at the tertiary hospital. Important determinants of unintended pregnancy include younger maternal age, unmarried status, previous childbirth and high number of pregnancies, previous caesarean birth and contraceptive usage prior to index pregnancy. Evidence-based interventions for prevention of unintended pregnancy including optimal client education and counselling, correct use of contraceptives should be consistently integrated and evaluated for continued uptake during the routing care for women especially during pre-conception care and the postpartum period. Further research with high methodological quality is recommended including qualitative data to better understand the interplay between unintended pregnancy and its determinants as well as typical use of contraception and the occurrence of unintended pregnancy. A more proactive approach in family planning education and counselling with specific emphasis on correct use of appropriate contraceptive methods is required to minimize the undesirable consequences of unintended pregnancy to the individuals, society and the country as a whole.

\section{Acknowledgements}

The authors are grateful to the pregnant women who consented and responded to the questionnaire. We thank $\operatorname{Dr}$ Ozge Tuncalp for reading through the manuscript and providing very important comments and guidance.

\section{Competing Interests Statement}

The authors declare that there are no competing or potential conflicts of interest.

\section{References}

Adu-Bonsaffoh, K, \& Seffah, J. D. (2015). Linking unintended pregnancy to the burden of pre-eclampsia in a tertiary hospital in Ghana. Journal of the West African College of Surgeons, 5(4), 17-29.

Adu-Bonsaffoh, Kwame, Samuel, O. A., Binlinla, G., \& Samuel, O. A. (2013). Maternal deaths attributable to hypertensive disorders in a tertiary hospital in Ghana. International Journal of Gynecology and Obstetrics, 123(2), 110-113. https://doi.org/10.1016/j.ijgo.2013.05.017

Agbeno, E. K., Morhe, E. S. K., \& Achampong, E. K. (2018). Study of the Factors Leading to Unintended Pregnancy in Women in Kumasi, Ghana. Asian Journal of Pregnancy and Childbirth, 1(1), 1-7. https://doi.org/10.9734/AJPCB/2018/44542

Ameyaw, E. K. (2018). Prevalence and correlates of unintended pregnancy in Ghana: Analysis of 2014 Ghana Demographic and Health Survey. Maternal Health, Neonatology and Perinatology, 4(1), 1-6. https://doi.org/10.1186/s40748-018-0085-1

Bearak, J., Popinchalk, A., Alkema, L., \& Sedgh, G. (2018). Global, regional, and subregional trends in unintended pregnancy and its outcomes from 1990 to 2014: estimates from a Bayesian hierarchical model. The Lancet Global Health, 6(4), e380-e389. https://doi.org/10.1016/S2214-109X(18)30029-9

Bradley, S. E. K., Croft, T. N., \& Rutstein, S. O. (2011). The Impact of Contraceptive Failure on Unintended Births and Induced Abortions: Estimates and Strategies for Reduction. DHS Analytical Studies No. 22, (september), i-ix, 1-43.

Campbell, O. M., \& Graham, W. J. (2006). Strategies for reducing maternal mortality: getting on with what works. Lancet, 368(9543), 1284-1299. https://doi.org/10.1016/S0140-6736(06)69381-1

De Coelho, E. A. C., De Andrade, M. L. S., Vitoriano, L. V. T., Da Silva, D. O., Gusmão, M. E. N., Do Nascimento, E. R., ... De Souza, J. J. (2012). Association between unplanned pregnancy and the socioeconomic context of 
women in the area of family health. ACTA Paulista de Enfermagem, 25(3), 415-422. https://doi.org/10.1590/S0103-21002012000300015

Eliason, S., Baiden, F., Yankey, B. A., \& Awusabo-Asare, K. (2014). Determinants of unintended pregnancies in rural Ghana. BMC Pregnancy and Childbirth, 14(1), 1-9. https://doi.org/10.1186/1471-2393-14-261

Engstrand, S., \& Kallner, K. H. (2018). Cost of unintended pregnancy in Sweden - a possibility to lower costs by increasing LARC usage. Contraception, 97(5), 445-450. https://doi.org/10.1016/j.contraception.2018.01.009

Exavery, A., Kanté, A. M., Njozi, M., Tani, K., Doctor, H. V., Hingora, A., \& Phillips, J. F. (2014). Predictors of mistimed, and unwanted pregnancies among women of childbearing age in Rufiji, Kilombero, and Ulanga districts of Tanzania. Reproductive Health, 11(1), 1-9. https://doi.org/10.1186/1742-4755-11-63

Fite, R. O., Mohammedamin, A., \& Abebe, T. W. (2018). Unintended pregnancy and associated factors among pregnant women in Arsi Negele Woreda, West Arsi Zone, Ethiopia 11 Medical and Health Sciences 1117 Public Health and Health Services 11 Medical and Health Sciences 1114 Paediatrics and Reproductive Medicin. BMC Research Notes, 11(1), 1-7. https://doi.org/10.1186/s13104-018-3778-7

Ganatra, B., Gerdts, C., Rossier, C., Johnson, B. R., Tunçalp, Ö., Assifi, A., ... Alkema, L. (2017). Global, regional, and subregional classification of abortions by safety, 2010-14: estimates from a Bayesian hierarchical model. The Lancet, 390(10110), 2372-2381. https://doi.org/10.1016/S0140-6736(17)31794-4

Ghana Statistical Service (GSS) 2011. (2012). Multiple Indicator Survey Ghana, Final report.

Ghana Statistical Service, G. H. S. and I. I. (2015). Ghana Health and Demographic Survey 2014.

Ghana Statistical Service, G. H. S. and I. I. (2018). Ghana Maternal Health Survey 2017. In Ghana Maternal Health Survey (GMHS) 2017.

Ghana Statistical Service, G. H. S. and I. M. (2009). Ghana Demographic and Health Survey 2008. In Ghana Demographic and Health Survey 2008.

Habib, M. A., Raynes-Greenow, C., Nausheen, S., Soofi, S. B., Sajid, M., Bhutta, Z. A., \& Black, K. I. (2017). Prevalence and determinants of unintended pregnancies amongst women attending antenatal clinics in Pakistan. BMC Pregnancy and Childbirth, 17(1), 1-10. https://doi.org/10.1186/s12884-017-1339-z

Haffejee, F., O’Connor, L., Govender, N., Reddy, P., Sibiya, M. N., Ghuman, S., ... Borg, D. (2018). Factors associated with unintended pregnancy among women attending a public health facility in KwaZulu-Natal, South Africa. South African Family Practice, 60(3), 79-83. https://doi.org/10.1080/20786190.2017.1396790

Johnson, F. A., \& Madise, N. J. (2011). Targeting women at risk of unintended pregnancy in Ghana: Should geography matter? Sexual and Reproductive Healthcare, 2(1), 29-35. https://doi.org/10.1016/j.srhc.2010.10.003

Lawani, L. O., Ekem, N. N., Eze, J. N., Ekwedigwe, K. C., Egede, J. O., \& Isikhuemen, M. E. (2018). The Prevalence and Determinants of Unintended Pregnancies Among Women in Abakaliki, Southeast Nigeria. Global Journal of Health Science, 10(10), 65. https://doi.org/10.5539/gjhs.v10n10p65

Loewenstein, G., \& Furstenberg, F. (1991). Is Teenage Sexual Behavior Rational? Journal of Applied Social Psychology, 21(12), 957-986. https://doi.org/10.1111/j.1559-1816.1991.tb00453.x

Maja, T. M. M. (2007). Factors impacting on contraceptive practices: Introduction and literature review: Part 1. Health SA Gesondheid, 12(1), 30-38. https://doi.org/10.4102/hsag.v12i1.241

Melese, T., Habte, D., Tsima, B. M., Mogobe, K. D., Chabaesele, K., Rankgoane, G., ... Moreri-Ntshabele, B. (2017). High levels of post-abortion complication in a setting where abortion service is not legalized. PLoS ONE, 12(1), 1-13. https://doi.org/10.1371/journal.pone.0166287

Mohammed, F., Musa, A., \& Amano, A. (2016). Prevalence and determinants of unintended pregnancy among pregnant woman attending ANC at Gelemso General Hospital, Oromiya Region, East Ethiopia: A facility based cross-sectional study. BMC Women's Health, 16(1), 10-16. https://doi.org/10.1186/s12905-016-0335-1

Mohllajee, A. P., Curtis, K. M., Morrow, B., \& Marchbanks, P. A. (2007). Pregnancy intention and its relationship to birth and maternal outcomes. Obstetrics and Gynecology, 109(3), 678-686. https://doi.org/10.1097/01.AOG.0000255666.78427.c5

Nyarko, S. H. (2019). Unintended Pregnancy among Pregnant Women in Ghana: Prevalence and Predictors. Journal of Pregnancy, 2019. https://doi.org/10.1155/2019/2920491 
Orr, S. T., Miller, C. A., James, S. A., \& Babones, S. (2008). Unintended pregnancy and preterm birth. Paediatric and Perinatal Epidemiology, 14(4), 309-313. https://doi.org/10.1046/j.1365-3016.2000.00289.x

Oulman, E., Kim, T. H. M., Yunis, K., \& Tamim, H. (2015). Prevalence and predictors of unintended pregnancy among women: An analysis of the Canadian Maternity Experiences Survey. BMC Pregnancy and Childbirth, 15(1), 1-8. https://doi.org/10.1186/s12884-015-0663-4

Polis, C. B., Bradley, S. E. K., Bankole, A., Onda, T., Croft, T., \& Singh, S. (2016). Typical-use contraceptive failure rates in 43 countries with Demographic and Health Survey data: Summary of a detailed report. Contraception, 94(1), 11-17. https://doi.org/10.1016/j.contraception.2016.03.011

Sapkota, P. V., Dhakal, L., \& Adhikari, R. S. (2015). Economic Burden of Unintended Pregnancies from Societal Perspective: a Case of Nepal. Combined Issue Economic Journal of Development Issues, 19(20), 83-99. Retrieved from https://pdfs.semanticscholar.org/e0c0/79488e438f03d2b35c20725bd11f75d714c2.pdf

Sanga, K., Mola, G., Wattimena, J., Justesen, A., \& Black, K. (2014). Unintended pregnancy amongst women attending antenatal clinics at the Port Moresby General Hospital. Australian and New Zealand Journal of Obstetrics and Gynaecology, 54(4), 360-365. https://doi.org/10.1111/ajo.12219

Santelli, J., Rochat, R., Hatfield-Timajchy, K., Gilbert, B. C., Curtis, K., Cabral, R., ... Schieve, L. (2003). The Measurement and Meaning of Unintended Pregnancy. Perspectives on Sexual and Reproductive Health, 35(2), 94-101. https://doi.org/10.1363/3509403

Sedgh, G., Singh, S., \& Hussain, R. (2014). Intended and unintended pregnancies worldwide in 2012 and recent trends. Studies in Family Planning, 45(3), 301-314. https://doi.org/10.1111/j.1728-4465.2014.00393.x

WHO, UNICEF, UNFPA, W. B. G. and the U. N. P. D. (2019). Trends in maternal mortality 2000 to 2017. In CC BY-NC-SA 3.0 IGO (Ed.), WHO, UNICEF, UNFPA, World Bank Group and the United Nations Population Division. Geneva.

World Health Organization (WHO). (2018). Family planning/contraception. Retrieved from World Health Organisation http://www.who.int/mediacentre/factsheets/fs351/en/

\section{Copyrights}

Copyright for this article is retained by the author(s), with first publication rights granted to the journal.

This is an open-access article distributed under the terms and conditions of the Creative Commons Attribution license (http://creativecommons.org/licenses/by/4.0/). 